\title{
Wild Type Sensitivity and Mutation Analysis for Resistance Risk to Fluopicolide in Phytophthora capsici
}

Xiao Hong Lu, Department of Plant Pathology, China Agricultural University, Beijing 100193, and Department of Plant Pathology, Michigan State University, East Lansing 48824; Mary K. Hausbeck, Department of Plant Pathology, Michigan State University; Xi Li Liu, Department of Plant Pathology, China Agricultural University; and Jianjun J. Hao, Department of Plant Pathology, Michigan State University

\begin{abstract}
Lu, X. H., Hausbeck, M. K., Liu, X. L., and Hao, J. J. 2011. Wild type sensitivity and mutation analysis for resistance risk to fluopicolide in Phytophthora capsici. Plant Dis. 95:1535-1541.

Crown, root, and fruit rot caused by Phytophthora capsici is an increasing problem for vegetable growers in Michigan and the United States. The newly registered fungicide fluopicolide is effective to limit crop loss but the potential for $P$. capsici to develop resistance is not well known. A laboratory study assessed the risk of $P$. capsici developing resistance to fluopicolide. Baseline sensitivity to fluopicolide was determined using 126 P. capsici Michigan isolates. Values of effective concentrations for $50 \%$ inhibition of mycelial growth ranged from 0.08 to $0.24 \mu \mathrm{g} / \mathrm{ml}$ and were distributed as a unimodal curve, indicating that all isolates were sensitive to fluopicolide. Mutants resistant to fluopicolide were obtained from five isolates by screening zoospores on

fluopicolide-amended $(5 \mu \mathrm{g} / \mathrm{ml})$ media at a mutation frequency above $1.0 \times 10^{-7}$. The mutant isolates were clustered with either intermediate (resistance factor $[\mathrm{RF}]=3.53$ to 77.91$)$ or high $(\mathrm{RF}=2481.40$ to 7034.79) resistance. Resistance was stable through 10 mycelial transfers on fungicide-free medium. All resistant mutants showed similar fitness in zoospore production, cyst germination, and virulence compared with their sensitive parents, with few exceptions. No cross-resistance was detected between fluopicolide and five other fungicides. There could be a moderately high risk of field populations of $P$. capsici developing resistance to fluopicolide, and populations should be monitored.
\end{abstract}

Phytophthora capsici is an oomycete pathogen infecting more than 50 species of plants $(13,24)$. Synthetic fungicides have been the growers' choice for controlling oomycete diseases in commercial production because crop rotation and other cultural strategies have provided only limited relief. The newly registered fungicide fluopicolide effectively controls oomycete plant pathogens such as $P$. infestans $(3,15,25), P$. capsici $(5,14,28)$, Pseudoperonospora cubensis (6,23), and Plasmopara viticola (30). However, fungicide resistance among oomycetes has been frequently reported $(1,2,7)$. Accordingly, fluopicolide may face the same risk and the risk of resistance developing in Phytophthora capsici needs to be assessed.

Fluopicolide is a systemic fungicide affecting $P$. capsici at all growth stages, including release and motility of zoospores, cyst germination, mycelial growth, and sporangial production (14). Fluopicolide-treated hypha or zoospores of $P$. infestans showed a fast perturbation of a spectrin-like protein (31) but the specific target protein of fluopicolide remains unclear. Based on the mode of action that affects mitosis and cell division, fluopicolide is classified by the Fungicide Resistance Action Committee into group $\mathrm{B}$, which contains benzimidazoles, zoxamide, and several other chemicals (1). However, these chemicals in group B are subgrouped based on their antimicrobial spectrums and other characteristics. Benzimidazoles are broad-spectrum fungicides targeting true fungi (29) and there have been many documented instances of pathogens developing resistance to them $(1,20,29)$. Zoxamide is mainly effective on oomycete pathogens (4), although some true fungi can be inhibited at high doses (32). There have been no reports of resistance to zoxamide with low to intermediate risk $(1,33)$.

Corresponding author: J. J. Hao, E-mail: jjhao@msu.edu

Accepted for publication 16 June 2011.

doi:10.1094/PDIS-05-11-0372

(C) 2011 The American Phytopathological Society
Because the registration of fluopicolide in the United States is relatively new, there are no data available on the potential of development of resistance in P. capsici or any other oomycete pathogens, although some antiresistance strategies are recommended for $P$. infestans (18). Research on cross resistance in oomycetes to fluopicolide and other fungicides would be invaluable in developing effective and long-sustaining management programs.

Monitoring and managing the development of fungicide resistance in the field requires establishing a baseline sensitivity of the pathogen population $(2,26)$, which requires a large number of $P$. capsici isolates for accuracy $(18,19)$. At present, few reports have described $P$. capsici sensitivity to fluopicolide using a limited number of isolates $(14,16)$. The objectives of this study were to (i) determine baseline sensitivity of $P$. capsici to fluopicolide; (ii) select resistant mutants under laboratory conditions; (iii) assess the risk of fluopicolide resistance by examining resistance level, stability, and fitness components of resistant mutants; and (iv) examine cross-resistance between fluopicolide and several oomycete fungicides.

\section{Materials and Methods}

Pathogen isolates and culture conditions. $P$. capsici isolates were all obtained from diseased cucurbitaceous and solanaceous crops in Michigan, except isolate NM13, which was obtained from China and included for comparison. The baseline sensitivity study included isolates SP98 (A2 mating type [MT]), 12889 (A1 MT), and SFF3 (A2 MT) (24), and 123 isolates collected in 2010. For the fluopicolide resistance study, isolates SP98, 12899, SFF3, NM13, MI2, and MI3 were used. MI2 and MI3 were isolated from spaghetti squash (Cucurbita pepo) in 2009. Isolates were transferred using a single-zoospore method and MT was determined for all isolates as described by Lamour and Hausbeck (17).

The following protocols were used throughout these studies for in vitro testing, unless otherwise described. Isolates were cultured on potato dextrose agar media (PDA; EMD Chemicals Inc., Gibbstown, $\mathrm{NJ}$ ) in petri dishes at $28^{\circ} \mathrm{C}$ in the dark for mycelial growth, and V8 juice agar (21) under constant fluorescent light at room temperature $\left(22 \pm 1^{\circ} \mathrm{C}\right)$ for sporangial production. Zoospore sus- 
pensions were prepared by flooding actively sporulating cultures with sterile distilled water and incubating at $4^{\circ} \mathrm{C}$ for $30 \mathrm{~min}$, followed by $30 \mathrm{~min}$ of incubation at room temperature (19). Zoospore concentration was measured and adjusted using a hemocytometer.

Baseline sensitivity of $\boldsymbol{P}$. capsici to fluopicolide. Baseline sensitivity of $126 \mathrm{P}$. capsici isolates (Table 1) was determined based on inhibition of mycelial growth on fluopicolide-amended PDA media. A formulated fluopicolide (Presidio, 39.5\% active ingredient [a.i.]; Valent BioScience Co., Libertyville, IL) was dissolved in dimethyl sulfoxide (DMSO) to prepare a stock solution $\left(1 \times 10^{4} \mu \mathrm{g} / \mathrm{ml}\right)$. Fungicide-amended agar plates were prepared by adding various volumes of fluopicolide stock solutions to PDA medium at $50^{\circ} \mathrm{C}$ before pouring. Final concentrations of fluopicolide were adjusted to $0,0.08,0.10,0.13,0.15,0.20,0.25$, and $0.30 \mu \mathrm{g} / \mathrm{ml}$, and final DMSO concentration was adjusted to $0.1 \%$ in PDA. Mycelial plugs ( $4 \mathrm{~mm}$ in diameter) were cut from the edge of actively growing colonies with a cork borer and placed myceliaside down on amended agar, three plates per concentration. After 4 days of incubation, colony diameters were measured in two perpendicular directions with the original mycelial plug diameter subtracted from this measurement. The averaged values of the two measurements were used for analysis. The experiment was performed two times independently.

Selection of fluopicolide-resistant isolates. Four single-zoospore isolates (SP98, 12889, SFF3, and NM13) and two bulk isolates (MI2 and MI3) of $P$. capsici were used to select fluopicolideresistant isolates. Zoospore suspensions of $P$. capsici isolates were made as described above. Zoospore concentrations were measured and adjusted to $5 \times 10^{6}$ zoospores $/ \mathrm{ml}$, and then $20 \mu \mathrm{l}$ of the suspension was spread on PDA agar amended with fluopicolide at $5 \mu \mathrm{g} / \mathrm{ml}$ (PDAF) in a $10-\mathrm{cm}$ petri dish. This concentration was approximately 10 times the minimal concentration that completely prohibited growth of sensitive (wild-type) isolates. PDA agar amended with $0.1 \%$ DMSO was used as a control and plated with $20 \mu \mathrm{l}$ of the suspension at $5 \times 10^{4}$ zoospores $/ \mathrm{ml}$. After incubation at $25^{\circ} \mathrm{C}$ in the dark for 5 days, colonies that survived on PDAF (diameters $>$ $10 \mathrm{~mm}$ ) were considered to be resistant to fluopicolide and the number of these colonies was counted for each plate. Resistant colonies were transferred to new PDA plates for later tests. Mutation frequency was calculated as a ratio of resistant colonies over total number of germinated cysts on control plates.

Characterization of fluopicolide-resistant isolates. Resistance factor and stability. Sensitivity of all $P$. capsici isolates resistant to fluopicolide was determined by measuring mycelial growth on PDA plates amended with various concentrations of fluopicolide, as described above. Two series of fluopicolide concentrations $(0,1$, $2,4,6,8$, and $10 \mu \mathrm{g} / \mathrm{ml}$ and 100, 200, 300, 400, 500, and 600 $\mu \mathrm{g} / \mathrm{ml}$ ) were used for isolates with low and high values, respectively, for effective concentrations for $50 \%$ inhibition of mycelial growth $\left(\mathrm{EC}_{50}\right)$. A resistance factor $(\mathrm{RF})$ was calculated as the ratio of $\mathrm{EC}_{50}$ values of a fungicide-resistant isolate relative to its parental isolate. After 10 successive transfers on fungicide-free PDA plates using five sensitive parental isolates and five randomly chosen corresponding resistant progeny isolates, including SP98 versus R8, 12889 versus R24, MI2 versus R56, and NM13 versus R78, the stability of resistant phenotypes was assessed by comparing RFs. The factor of sensitivity change (FSC) to fluopicolide was calculated as the ratio of $\mathrm{EC}_{50}$ values (the isolates from the 10th/1st transfer). The experiment was conducted twice. The five pairs of wild sensitive isolates and their fluopicolide-resistant derivatives were also used in fitness tests, including the effect of temperature, zoospore production and cyst germination in vitro, and virulence in zucchini fruit and pepper seedlings.

Effect of temperature on mycelial growth. Five resistant isolates and their parents (as described above) were incubated on PDA media at $10,15,20,25$, and $35^{\circ} \mathrm{C}$. Colony diameters were measured after 7 days of incubation in the dark, and two measurements were averaged to represent mycelial growth. There were four replicated plates for each treatment and the experiment was conducted twice.

Zoospore production and cyst germination in vitro. Zoospore production was assayed (19) by excising 10 plugs ( $4 \mathrm{~mm}$ in diameter) from the culture edge and 10 plugs from the area near the initial inoculum plug using a cork borer, and placing all 20 culture plugs in a $15-\mathrm{ml}$ centrifuge tube containing $10 \mathrm{ml}$ of sterile distilled water to produce zoospores as described above. The concentration of zoospores was determined with a hemocytometer. Cystospore germination was measured on $2 \%$ water agar medium under a microscope after incubation of zoospore suspensions for $12 \mathrm{~h}$ at $25^{\circ} \mathrm{C}$ in the dark. A germinated cystospore was confirmed if the length of germ tube was longer than the cyst diameter. For each isolate, 100 cysts were examined and two independent experiments were performed.

Virulence on zucchini fruit and pepper seedlings. Virulence of $P$. capsici isolates was determined by inoculation assays on detached zucchini (C. pepo 'Black Beauty') fruit and pepper (Capsicum annuum 'Sweet Banana') seedlings. Zucchini fruit were inoculated using the method previously described by Granke et al. (12), with slight modifications. Fruit were washed with tap water, disinfested with $10 \%$ bleach $(0.62 \% \mathrm{NaClO})$ for $5 \mathrm{~min}$, rinsed with sterile water, dried at room temperature, and placed in a clear plastic box with moist paper towels placed at the bottom to maintain high relative humidity. Three small superficial wounds were made equidistant with a sterile needle for each fruit. Agar plugs (4 mm in diameter) cut from the margin of actively growing colonies on PDA plates were placed mycelia-side down on the wound. Zucchini were inoculated using PDA plugs (no $P$. capsici culture) as controls. The inoculated zucchini fruit were incubated at room temperature $\left(22 \pm 1^{\circ} \mathrm{C}\right)$ for 3 days (16-h photoperiod). The lesion

Table 1. Phytophthora capsici isolates collected in Michigan for study of baseline sensitivity to fluopicolide

\begin{tabular}{|c|c|c|c|c|}
\hline \multirow[b]{2}{*}{ Location } & \multirow[b]{2}{*}{ Host (species) } & \multicolumn{3}{|c|}{ Number of isolates } \\
\hline & & Mating type A1 & Mating type A2 & Total \\
\hline Decatur & Cucumber (Cucumis sativus) & 4 & 1 & 5 \\
\hline Decatur & Pepper (Capsicum annuum) & 2 & 0 & 2 \\
\hline Decatur & Squash (Cucurbita pepo) & 3 & 7 & 10 \\
\hline Decatur & Squash & 4 & 4 & 8 \\
\hline South Haven & Pepper & 15 & 6 & 21 \\
\hline Lawrence & Pepper & 8 & 17 & 25 \\
\hline Newaygo County & Squash & 0 & 1 & 1 \\
\hline Cass County & Cucumber & 3 & 1 & 4 \\
\hline Benton & Pepper & 6 & 5 & 11 \\
\hline Benton & Squash & 13 & 7 & 20 \\
\hline Hartford & Pepper & 6 & 8 & 14 \\
\hline Unknown & Squash & 2 & 0 & 2 \\
\hline Unknown & Pumpkin (Cucurbita maxima) & 1 & 0 & 1 \\
\hline Unknown & Cucumber & 0 & 1 & 1 \\
\hline Unknown & Pepper & 1 & 0 & 1 \\
\hline Total & $\ldots$ & 68 & 58 & 126 \\
\hline
\end{tabular}


area that developed on zucchini fruit was estimated by measuring the diameter of water-soaked lesions and mycelial colonies perpendicularly.

Pepper seedling inoculation and disease scoring were performed with the method described by Glosier et al. (10), with minor modifications. Five seedlings were grown in each of four pots (10 by $10 \mathrm{~cm}^{2}$ on the top). At the six-true-leaf stage, $10 \mathrm{ml}$ of a $P$. capsici zoospore suspension $\left(2 \times 10^{4}\right.$ zoospores $\left./ \mathrm{ml}\right)$ was applied to the soil near the stem for one pot, with three replicated pots for each treatment. Inoculated plants were incubated in a growth chamber (temperature $=23^{\circ} \mathrm{C}$, humidity $=65 \pm 5 \%$, and photoperiod $=16 \mathrm{~h}$ of light). Seven days post inoculation, disease severity for all plants was rated on a scale of 0 to $5(0=$ healthy plant, $1=$ leaf yellowing and no stem necrosis, $2=$ minor stem necrosis, $3=$ moderate stem necrosis and some wilting, $4=$ severe stem necrosis and severe wilting, and $5=$ dead plant).

To confirm the resistance of the mutant, the zucchini fruit were kept in a fluopicolide solution for $5 \mathrm{~min}$ at concentrations of 50 , 100,200 , or $500 \mu \mathrm{g} / \mathrm{ml}$, followed by inoculation with agar plugs of the wild-type isolates (SP98, 12889, MI3 and NM13) and intermediately (R40 and R78) and highly (R8 and R72) resistant mutants on the fruit, as described above. Disease lesions with water soaking or mycelial growth were observed on zucchini fruit after 3 days of incubation.

Cross-resistance to other oomycete fungicides. Six sensitive, six intermediately resistant, and six highly resistant isolates of $P$. capsici were tested for sensitivity to five oomycete fungicides representing different modes of action, using the mycelia growth inhibition method described above. All formulated fungicides were

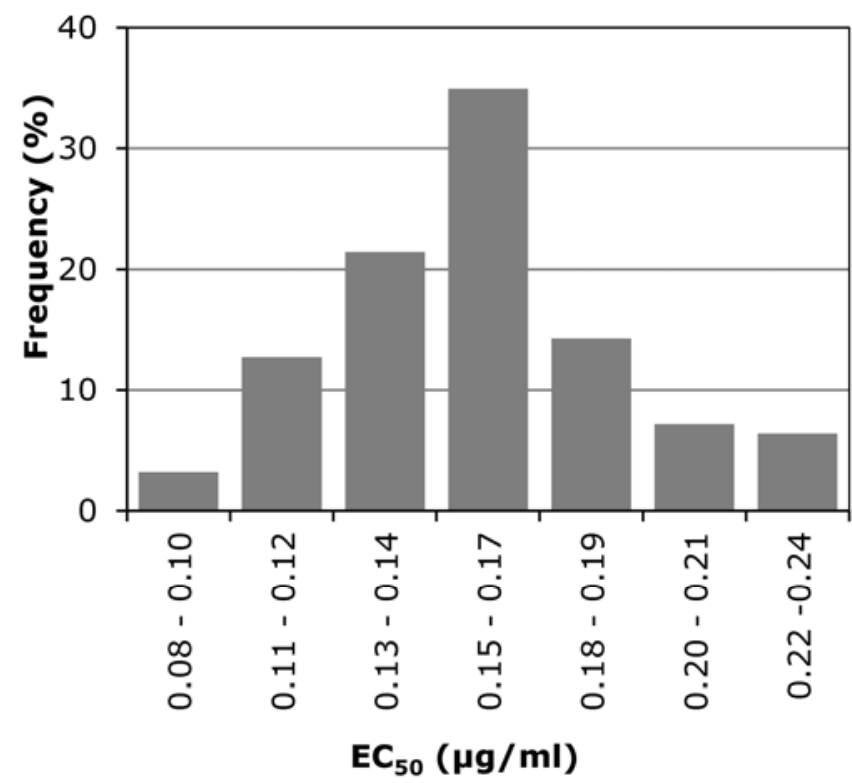

Fig. 1. Distribution of fluopicolide sensitivity, described as effective concentration for $50 \%$ inhibition of mycelial growth $\left(\mathrm{EC}_{50}\right)$ of 126 Phytophthora capsici isolates, collected from Michigan vegetable crops in areas without a history of fluopicolide application. dissolved in DMSO as described earlier and added to PDA to yield the following final concentrations: cyazofamid (RAMAN, 34.5\% a.i.; FMC Corporation, Philadelphia) at 0, 0.01, 0.05, 0.1, 0.5 and 1 $\mu \mathrm{g} / \mathrm{ml}$; mandipropamid (Revus, $23.4 \%$ a.i.; Syngenta Crop Protection, Inc. Greensboro, NC) at $0,0.008,0.01,0.012,0.014,0.016$, and $0.018 \mu \mathrm{g} / \mathrm{ml}$; mefenoxam (Ridomil Gold, $47.6 \%$ a.i.; Novartis Crop Protection, Inc. Greensboro, NC) at 0, 0.005, 0.1, 0.3, 0.6, 1, and $5 \mu \mathrm{g} / \mathrm{ml}$; zoxamide (Zoxium, $80 \%$ a.i.; Gowan Co., Yuma, AZ) at $0,0.004,0.008,0.01,0.02,0.04$ and $0.06 \mu \mathrm{g} / \mathrm{ml}$; and azoxystrobin (Heritage, $50 \%$ a.i.; Syngenta Crop Protection) at $0,1,2$, $3,4,5$, and $6 \mu \mathrm{g} / \mathrm{ml}$ plus a technical grade of salicylhydroxamic acid (99\%, Sigma-Aldrich, St. Louis) at $100 \mu \mathrm{g} / \mathrm{ml}$.

Statistical analysis. Data were analyzed with SAS software (version 9.2; SAS Institute Inc. Cary, NC). $\mathrm{EC}_{50}$ values were calculated using regression analysis (using procedure REG) of percent growth inhibition against the logarithmic values of fungicide concentrations. Procedure GLM was used for an analysis of variance, and Student's $t$ test was used for comparisons of means. For crossresistance tests, $\mathrm{EC}_{50}$ values were log transformed, and then Spearman rank correlation was used to analyze cross-resistance relationships between fluopicolide and each of the other five fungicides with logarithmic transformation of $\mathrm{EC}_{50}$ values.

\section{Results}

Baseline sensitivity of $P$. capsici isolates to fluopicolide. Among the 126 Michigan isolates of P. capsici, there were 68 isolates with A1 MT and 58 isolates with A2 MT (Table 1) and no significant differences for $\mathrm{EC}_{50}$ values between two MTs based on the $t$ test $(\alpha=0.05)$. $\mathrm{EC}_{50}$ values of the population ranged from 0.08 to $0.24 \mu \mathrm{g} / \mathrm{ml}$, with a mean of $0.16 \mu \mathrm{g} / \mathrm{ml}$, and were distributed as a unimodal curve (Fig. 1), suggesting that all wild-type isolates were sensitive to fluopicolide $\left(\mathrm{EC}_{50} \leq 0.24 \mu \mathrm{g} / \mathrm{ml}\right)$.

Selection of fluopicolide-resistant mutants of $P$. capsici. Fluopicolide-resistant mutants were obtained from five of six wild-type isolates regardless of MTs and the geographical source (Table 2). Resistant mutants were derived at frequencies of the same order of magnitude (approximately one resistant colony per $1 \times 10^{7}$ zoospores tested) for single-zoospore and bulk-culture isolates (Table 2).

Characterization of fluopicolide-resistant mutants of $\boldsymbol{P}$. capsici. $R F$ and stability. Among the fluopicolide-resistant mutants, RFs ranged from 3.53 to 7034.79 . The resistance to fluopicolide was considered as intermediately resistant if RF was $<100$ and highly resistant if $\mathrm{RF}$ was $\geq 100$. For isolates with intermediate resistance, RFs ranged from 3.53 to 77.91 , corresponding to $\mathrm{EC}_{50}$ values from 0.38 to $9.12 \mu \mathrm{g} / \mathrm{ml}$ (Fig. 2). For highly resistant isolates, RFs ranged from 2481.40 to 7034.79 , corresponding to $\mathrm{EC}_{50}$ values from 265.5 to $752.7 \mu \mathrm{g} / \mathrm{ml}$, respectively (Fig. 2). No mutants fell within the range of 78 to $2,480 \mathrm{RFs}$, which separated the intermediately and highly resistant groups of mutants distinctively (Fig. 2). After 10 transfers on fungicide-free PDA media, $\mathrm{EC}_{50}$ values of all intermediately resistant isolates increased; for the highly resistant isolates, $\mathrm{EC}_{50}$ values decreased but $\mathrm{RFs}$ were all $>$ 1,000 (Table 3).

Effect of temperature on mycelial growth. There was no discernable difference between growth of fluopicolide-resistant mutants

Table 2. Phytophthora capsici wild-type isolates and their mutant derivatives resistant to fluopicolide ${ }^{a}$

\begin{tabular}{|c|c|c|c|c|c|c|}
\hline \multirow[b]{2}{*}{ Wild-type isolates } & \multirow[b]{2}{*}{ Tested zoospores $\left(\times 10^{7}\right)$} & \multirow[b]{2}{*}{ Germination rate (\%) } & \multicolumn{2}{|c|}{ Derived mutants } & \multirow[b]{2}{*}{ Total } & \multirow[b]{2}{*}{ Mutation rate $\left(\times 10^{-7}\right)$} \\
\hline & & & Intermediately resistant & Highly resistant & & \\
\hline SP98 & 21.30 & 70.86 & 11 & 9 & 20 & 1.32 \\
\hline 12889 & 9.50 & 83.33 & 27 & 8 & 35 & 4.42 \\
\hline MI2 & 13.40 & 56.79 & 4 & 4 & 8 & 1.05 \\
\hline MI3 & 8.33 & 55.25 & 4 & 7 & 11 & 2.39 \\
\hline NM13 & 5.13 & 79.89 & 2 & 3 & 5 & 1.22 \\
\hline SFF3 & 4.40 & 83.64 & - & - & 0 & - \\
\hline
\end{tabular}

${ }^{a}$ Resistance level to fluopicolide was determined based on resistance factor (RF), which was calculated as the ratio of values of effective concentration for $50 \%$ inhibition $\left(\mathrm{EC}_{50}\right)$ of an isolate relative to its parent. Resistance of $P$. capsici isolates was grouped into intermediate $(\mathrm{RF}<100)$, or high $(\mathrm{RF} \geq 100)$ resistance; $-=$ data not available. 
and their parents (Table 4). At 10 temperature points, the parents grew faster than the mutant derivatives but, at 9 temperature points, resistant mutants grew faster than their parents $(\alpha=0.05)$. At the other temperatures, there were no significant differences in mycelial growth between the parents and derived mutants of $P$. capsici

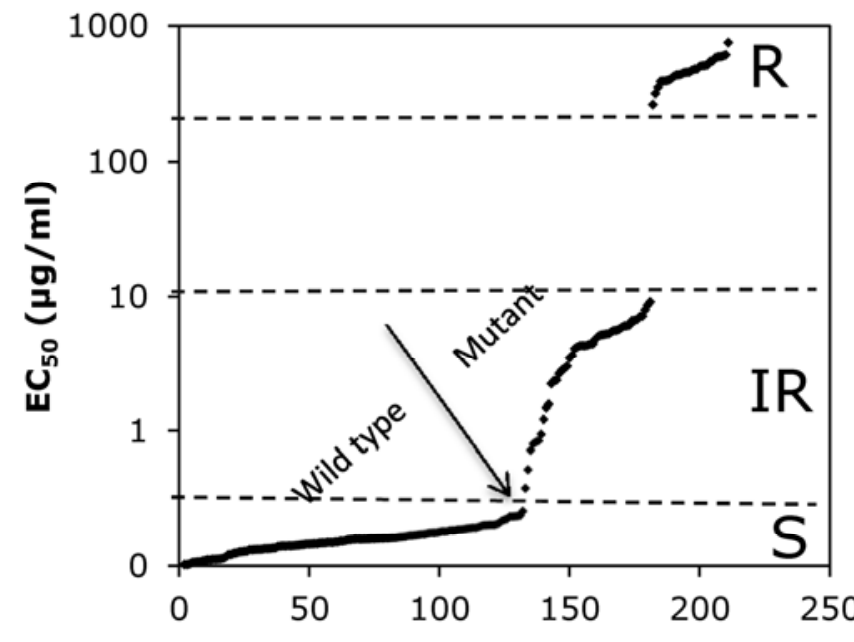

Isolates

Fig. 2. Distribution of fluopicolide sensitivity, measured as effective concentration values for $50 \%$ inhibition of mycelial growth $\left(\mathrm{EC}_{50}\right)$ of wild-type and mutant isolates of Phytophthora capsici. Isolates are grouped by fluopicolide sensitivity, separated by broken horizontal lines: sensitive (S), intermediately resistant (IR), and highly resistant $(R)$. $S$ isolates were all wild-type isolates collected from Michigan (left side of the arrow); $\mathbb{R}$ and $\mathrm{R}$ isolates were derived from five of $\mathrm{S}$ isolates (right side of the arrow).
(Table 4). For example, resistant mutant R8 grew more slowly than its parent SP98 at 10 and $25^{\circ} \mathrm{C}, \mathrm{R} 24$ grew more slowly than its parent 12889 at 30 and $35^{\circ} \mathrm{C}, \mathrm{R} 56$ grew more slowly than its parent $\mathrm{MI} 2$ only at $15^{\circ} \mathrm{C}$, and R70 grew significantly more slowly than its parent MI3 only at $15^{\circ} \mathrm{C}$. However, R78 grew faster than parental isolate $\mathrm{NM} 13$ at $15^{\circ} \mathrm{C}$. In general, the growth of most resistant mutants did not differ from that of their parental isolates at tested temperatures (Table 4).

Zoospore production and cyst germination in vitro. There were no differences in zoospore production between resistant mutants and their corresponding sensitive parental isolates, except for isolate R8 (resistant), which produced significantly more zoospores than SP98 (wild-type parent) (Table 5). Three of five resistant mutants had higher cyst germination rates than their corresponding wild-type parental isolate, R78 had a lower germination rate than its parent (NM13), and R24 was similar to its parent (12889) (Table 5).

Virulence on zucchini fruit and pepper seedlings. There was no difference in virulence (lesion and mycelial colony diameters) of all resistant mutants compared with their corresponding parents when tested on zucchini fruit. Disease severity of the mutants tested was not different compared with sensitive parental isolates on pepper seedlings, with the exceptions of R70 versus MI3, in which the mutant R70 had statistically lower disease severity than sensitive parent MI3 (Table 5). Three days after inoculation with $\mathrm{R} 8$, a mutant with high RF, the fruit treated in fluopicolide solution showed the same size of symptom compared with the nontreated control, indicating that the infection of these isolates tested was not affected by application of fluopicolide but, when R78, a mutant with lower RF, was used for inoculation, the infection was partially affected (Fig. 3). Results were similar for R40 and R72, respectively (data not shown). The infection by all sensitive isolates tested was completely inhibited with fluopicolide at $100 \mu \mathrm{g} / \mathrm{ml}$ (Fig. 3).

Table 3. Resistance stability of fluopicolide-resistant mutants of Phytophthora capsici $i^{\mathrm{a}}$

\begin{tabular}{|c|c|c|c|c|c|c|c|c|}
\hline \multirow[b]{2}{*}{ WT isolate ${ }^{d}$} & \multicolumn{2}{|c|}{$\mathrm{EC}_{50}(\mu \mathrm{g} / \mathrm{ml})^{\mathrm{b}}$} & \multirow[b]{2}{*}{ Mutants } & \multicolumn{2}{|c|}{$\mathrm{EC}_{50}(\mu \mathrm{g} / \mathrm{ml})$} & \multicolumn{2}{|c|}{$\mathbf{R F}^{\mathbf{c}}$} & \multirow[b]{2}{*}{ FSC $^{e}$} \\
\hline & T1 & T10 & & T1 & T10 & T1 & T10 & \\
\hline SP98 & 0.16 & 0.20 & R8 & 612.82 & 213.67 & $3,920.78$ & $1,042.80$ & 0.35 \\
\hline 12889 & 0.11 & 0.11 & R24 & 2.65 & 4.73 & 24.74 & 42.76 & 1.79 \\
\hline MI2 & 0.12 & 0.12 & R56 & 7.05 & 7.76 & 60.25 & 64.59 & 1.10 \\
\hline MI3 & 0.11 & 0.12 & R70 & 580.72 & 430.89 & $5,175.78$ & $3,575.86$ & 0.74 \\
\hline NM13 & 0.14 & 0.14 & R78 & 2.23 & 2.30 & 15.42 & 16.05 & 1.03 \\
\hline
\end{tabular}

${ }^{\mathrm{a}} \mathrm{T} 1$ and $\mathrm{T} 10=$ the first and tenth transfers of culture on PDA media.

${ }^{\mathrm{b}} \mathrm{EC}_{50}=$ effective concentration of fluopicolide for $50 \%$ inhibition of mycelial growth in $P$. capsici.

${ }^{\mathrm{c}} \mathrm{RF}=$ resistance factor, a ratio of $\mathrm{EC}_{50}$ values for an isolate (mutant) relative to the parental isolate.

${ }^{\mathrm{d}} \mathrm{WT}=$ wild type.

${ }^{\mathrm{e}} \mathrm{FSC}=$ factor of sensitivity change for fluopicolide mutants only, a ratio of $\mathrm{EC}_{50}$ values of the 1st/10th transferred culture.

Table 4. Effect of temperature on mycelial growth (colony diameter in millimeter) of Phytophthora capsici wild-type and fluopicolide-resistant mutants on potato dextrose agar plates

\begin{tabular}{|c|c|c|c|c|c|c|c|}
\hline \multirow[b]{2}{*}{ Isolate } & \multirow[b]{2}{*}{ Sensitivity $^{\mathrm{b}}$} & \multicolumn{6}{|c|}{ Colony diameter $(\mathrm{mm})$ at each temperature ${ }^{\mathrm{a}}$} \\
\hline & & $10^{\circ} \mathrm{C}$ & $15^{\circ} \mathrm{C}$ & $20^{\circ} \mathrm{C}$ & $25^{\circ} \mathrm{C}$ & $30^{\circ} \mathrm{C}$ & $35^{\circ} \mathrm{C}$ \\
\hline SP98 & $\mathrm{S}_{1}$ & $12.1 *$ & 19.3 & 52.1 & $67.9 *$ & 63.6 & 44.6 \\
\hline R8 & $\mathrm{R}_{1}$ & 9.9 & $33.1 *$ & 53.4 & 63.1 & $66.6^{*}$ & 47.0 \\
\hline 12889 & $\mathrm{~S}_{2}$ & 5.1 & 33.3 & 53.4 & 62.1 & $72.3^{*}$ & 47.3 \\
\hline R24 & $\mathrm{IR}_{2}$ & $15.4^{*}$ & 33.8 & 54.3 & 61.3 & 65.1 & 42.8 \\
\hline MI2 & $\mathrm{S}_{3}$ & $16.9 *$ & $20.9 *$ & 53.6 & 65.4 & 75.5 & 57.3 \\
\hline R56 & $\mathrm{IR}_{3}$ & 15.4 & 19.3 & 52.1 & $67.9 *$ & 76.4 & 57.0 \\
\hline MI3 & $\mathrm{S}_{4}$ & 16.6 & $27.1 *$ & 50.8 & 63.6 & 66.1 & 52.3 \\
\hline R70 & $\mathrm{R}_{4}$ & 15.0 & 21.3 & $53.6^{*}$ & $68.0 *$ & $75.3 *$ & $61.0^{*}$ \\
\hline NM13 & $\mathrm{S}_{5}$ & 16.6 & 21.3 & $53.4^{*}$ & $67.3^{*}$ & $79.0^{*}$ & $62.0 *$ \\
\hline R78 & $\mathrm{IR}_{5}$ & 17.4 & $27.4^{*}$ & 50.3 & 61.1 & 66.5 & 50.3 \\
\hline
\end{tabular}

${ }^{a}$ Colony diameter was measured 7 days post inoculation, except at $10^{\circ} \mathrm{C}$, when measurement was done 30 days post inoculation due to its slow growth Student $t$ test was performed for each pair (group) of wild-type parent (S) and its derived mutant of P. capsici at significance level $\alpha=0.05$. Symbol "**" indicates a significantly higher value.

${ }^{b}$ Sensitivity to fluopicolide was classified as sensitive (S), intermediately resistant (IR, with resistant factor $[R F]<100$ ), and resistant (R, with RF $\geq 100$ ) groups. Subscripted numbers indicate groups of parental and derived mutant isolates (IR or R). 
Cross-resistance to other oomycete fungicides in $\boldsymbol{P}$. capsici. In rank correlation analysis for cross-resistance, all $P$ values were higher than 0.05 , suggesting that there was no correlation between fluopicolide and any of the other five fungicides tested (azoxystrobin, mandipropamid, cyazofamid, zoxamide, and mefenoxam). Therefore, there was no evidence of cross-resistance between fluopicolide and any of the five tested fungicides (Fig. 4).

\section{Discussion}

A baseline of fluopicolide sensitivity in $P$. capsici was established using 126 field isolates from Michigan; this information can be used in continued field monitoring of fungicide resistance. The unimodal distribution at low levels of $\mathrm{EC}_{50}$ values demonstrated that fluopicolide resistance has not developed in the field. The population of $P$. capsici isolates used in this study confirmed a similar result of $\mathrm{EC}_{50}$ values of isolates obtained from the southeastern United States $(14,16)$. However, the large number of isolates used in the present study makes it possible to establish a full spectrum of sensitivity distribution with high confidence.

This study is the first to report fluopicolide resistance of $P$. capsici using resistant mutants. The technique of generating mutants by screening zoospores on fungicide-amended media is representative of what could happen naturally in the field. The frequency of resistance to fluopicolide $\left(10^{-7}\right)$ is much higher than that of iprovalicarb $\left(10^{-12}\right)$, an oomycete fungicide belonging to carboxylic acid amides (CAA) (19). Resistant mutants were obtained from both single-spore isolates and bulk isolates in similar frequency, with the exception of isolate SFF3, suggesting that both kinds of isolates are equally effective at generating resistant mutants. It is not clear why resistant mutants were not obtained from SFF3.

In this study, P. capsici mutants resistant to fluopicolide retain the resistance persistently without fluopicolide selection pressure, indicating that the resistance is not acquired adaptively but is a result of gene expression, although inheritance of fluopicolide resistance needs to be further studied. Fungicide resistance can be classified into monogenic and polygenic resistance, based on the number of genes involved (8). A field population of a pathogen with monogenic resistance exhibits several distinct subpopulations, and the resistant subpopulation usually has high RF values $(>100)$ and a high inherent risk of developing fungicide resistance, such as to benzimidazoles (20) and phenylamide $(7,27)$. In contrast, a population with polygenic resistance usually shows a continuous distribution of fungicide sensitivity and lower RF values, as evidenced by resistance to demethylation inhibitors (7), and is not likely to result in sudden failures of fungicide efficacy. In the present study, the generated mutants were clustered in two distinctive groups based on RF values. The population of resistant mutants has high RF values $(>1,000)$, suggesting that fluopicolide resistance is controlled monogenically and, therefore, may have a high inherent risk.
Due to the diploid nature of oomycetes, the level of resistance risk is highly affected by the type of inheritance (dominant, semidominant, or recessive) when fungicide resistance is controlled monogenically. Phenylamide resistance is controlled by a semidominant nuclear gene (27), resulting in a high resistance frequency to metalaxyl $\left(10^{-6}\right.$ under laboratory conditions; 33$)$ and disease control failure with many pathogens $(11,13,22)$. In contrast, it is difficult to develop a resistant mutant population when fungicide resistance is controlled by a single recessive gene (9), such as with CAA fungicides. Isolates resistant to CAAs in the field have been detected only for Plasmopara viticola (9) and Pseudoperonospora cubensis (34). In this study, both spontaneously intermediate and high resistances were observed, suggesting that fluopicolide resistance may be controlled by semidominant genes and, therefore, Phytophthora capsici isolates have a higher possibility to develop resistance in the field. For this situation, sexual recombination is not an issue because dominant or semidominant genes are always expressed.

Fitness of resistant isolates is also an important factor when evaluating the risk of fungicide resistance. Resistant mutants of $P$. capsici showed strong adaptation ability at different stages in the life cycle, including mycelial growth, sporulation, germination, and, more importantly, virulence. This adaptability ensures that the mutants will survive and infect plants successfully with competitive ability. Fluopicolide resistance of these mutants was confirmed by infection of inoculated zucchini regardless of the rate of fluopicolide applied to the fruit, using several isolates. Thus, a fluopi-

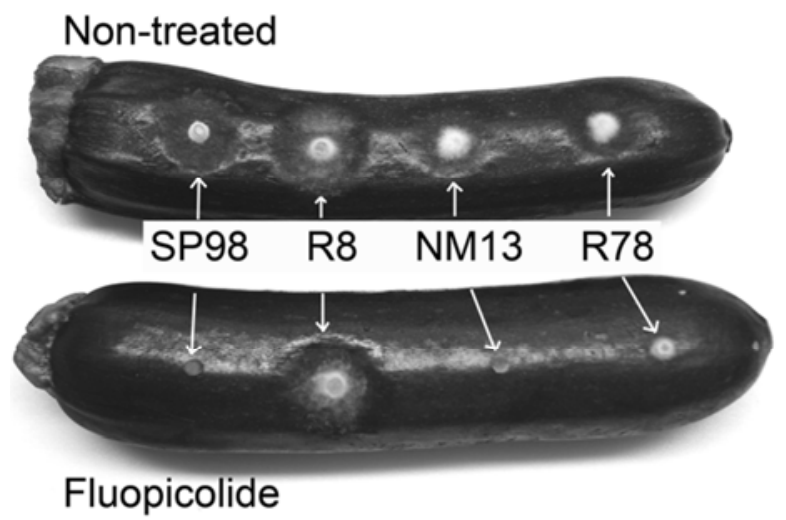

Fig. 3. Effect of fluopicolide on Phytophthora capsici isolates SP98, NM13 (wild type, fluopicolide-sensitive), R78 (intermediately resistant to fluopicolide), and R8 (highly resistant to fluopicolide). Zucchini fruit were treated in sterile distilled water (non-treated), or fluopicolide solution $(100 \mu \mathrm{g} / \mathrm{ml})$, followed by inoculation with a mycelial plug of each isolate as indicated by arrows.

Table 5. Sporulation, germination, and virulence of fluopicolide-resistant mutants and the corresponding parental isolates of Phytophthora capsici ${ }^{\mathrm{a}}$

\begin{tabular}{|c|c|c|c|c|c|c|}
\hline \multirow[b]{2}{*}{ Group $^{c}$} & \multirow[b]{2}{*}{ Isolate } & \multirow[b]{2}{*}{ Sporulation $\left(\times 10^{5}\right.$ zoospore $\left./ \mathrm{ml}\right)$} & \multirow[b]{2}{*}{ Rate $(\%)^{d}$} & \multicolumn{2}{|c|}{ Virulence (diameter, $\mathbf{m m})^{\mathbf{b}}$} & \multirow[b]{2}{*}{ Disease severity } \\
\hline & & & & Lesion & Mycelia & \\
\hline I & SP98 & 3.81 & 70.9 & 38.3 & 31.8 & 2.9 \\
\hline I & R8 & $4.45^{*}$ & $82.4 *$ & 39.8 & 32.3 & 3.3 \\
\hline II & 12889 & 3.61 & 83.3 & 38.7 & 27.9 & 3.0 \\
\hline II & R24 & 3.89 & 81.8 & 36.9 & 27.4 & 3.1 \\
\hline III & MI2 & 3.86 & 56.8 & 37.1 & 26.7 & 3.6 \\
\hline III & R56 & 3.55 & $84.2 *$ & 33.7 & 22.3 & 4.0 \\
\hline IV & MI3 & 5.53 & 55.3 & 32.3 & 17.9 & $3.6^{*}$ \\
\hline IV & R70 & 6.61 & $82.1 *$ & 33.4 & 19.1 & 2.8 \\
\hline V & NM13 & 7.85 & 79.9* & 39.7 & 30.8 & 3.8 \\
\hline V & R78 & 8.15 & 70.9 & 35.9 & 27.5 & 3.5 \\
\hline
\end{tabular}

${ }^{\text {a }}$ Student $t$ test was performed for each pair (group) of mutant (plain text) and parent (bold text) of $P$. capsici at significance level $\alpha=0.05$; * indicates a significantly higher value.

${ }^{\mathrm{b}}$ Virulence on zucchini fruit was rated by measuring the lesion size (diameter) and pathogen growth (diameter of mycelial colony).

${ }^{\mathrm{c}}$ Each group contains a parental (wild type) and derived mutant resistant to fluopicolide.

${ }^{\mathrm{d}}$ Cyst germination rate.

${ }^{\mathrm{e}}$ Disease severity in pepper seedlings was evaluated on a scale of 0 to $5(0=$ healthy plant, $1=$ leaf yellowing and no stem necrosis, $2=$ minor stem necrosis, $3=$ moderate stem necrosis and some wilting, $4=$ severe stem necrosis and severe wilting, and $5=$ dead plant). 
colide-resistant subpopulation could establish, reproduce, and dominate once it appears in the field following a certain selection pressure of fluopicolide.

High fungicidal activity, monogenic type of resistance, and high fitness of resistant mutants indicate a high risk of inherent resistance of fluopicolide in P. capsici. To reduce the selection pressure, limiting the dose and numbers of applications for each season and applying fluopicolide in a preventive manner will be helpful. Because no cross-resistance has been found in the present study or in a previous report (31), application of fluopicolide alternated and mixed with other oomycete fungicides will help to reduce the resistance risk and corresponding economic losses.
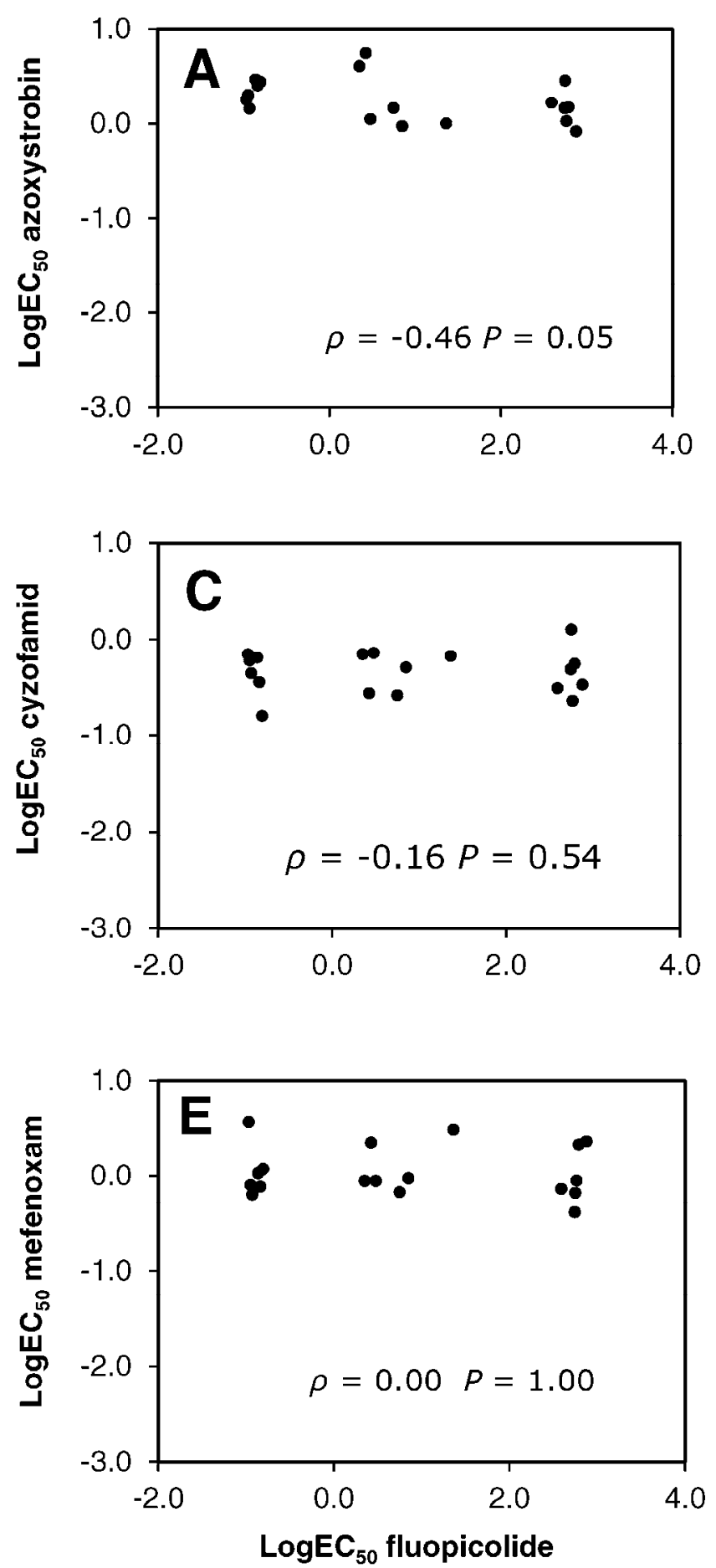

\section{Acknowledgments}

This research was partially funded through the United States Department of Agriculture Specialty Crop Research Initiative program (NIFA grant number 2008-51180-04881) and the China Scholarship Council (2008635040). We thank J. Byrne for providing some disease samples, B. Cortright for technical assistance, R. Goldy for helping to locate fields and contact growers, and $\mathrm{N}$. Rosenzweig and S. Linderman for a critical review of this manuscript.

\section{Literature Cited}

1. Anonymous. 2011. FRAC Code List: Fungicides Sorted by Mode of Action (including FRAC Code numbering). Fungicide Resistance Action Committee, Basel, Switzerland.

2. Brent, K. J., and Hollomon, D. W. 2007. Fungicide Resistance: The Assessment of Risk. FRAC Monogr. No. 2. Global Crop Protection
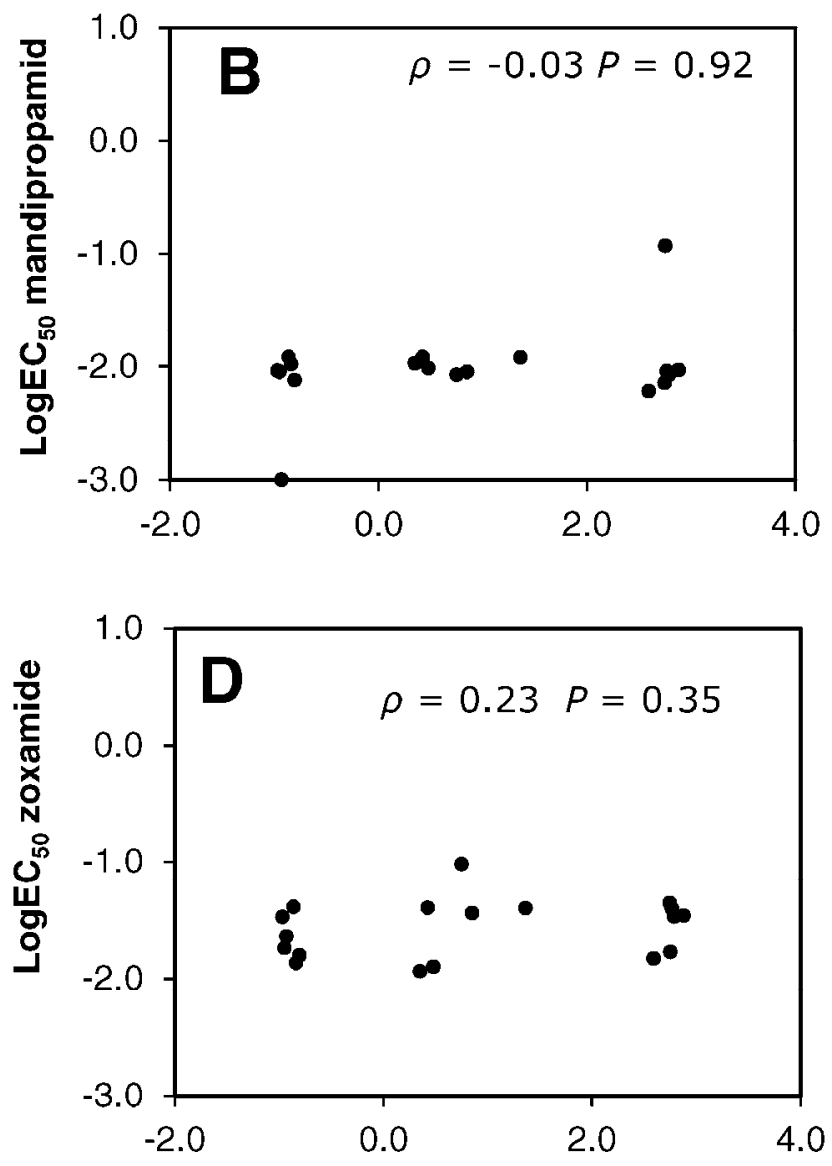

$\operatorname{LogEC}_{50}$ fluopicolide

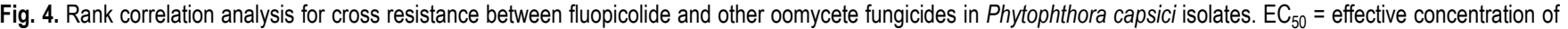
fluopicolide for $50 \%$ inhibition of mycelial growth of Phytophthora capsici. Values on $x$ and $y$ axes were logarithmic transformation of EC $\mathrm{C}_{50}$ values. Correlation between fluopicolide and A, azoxystrobin; B, mandipropamid; C, cyazofamid; D, zoxamide; and E, mefenoxam were conducted. 
Federation, Brussels.

3. Cooke, L. R., and Little, G. 2006. Evaluation of fluopicolide-containing formulations for the control of potato late blight in Northern Ireland. Pflanzenschutz Nachr. Bayer 59:303-316.

4. Egan, A. R., Mithelotti, E. L., Yong, D. H., Wilson, W. J., and Mattioda, H. 1998. RH-7281: a novel fungicide for control of downy mildew and late blight. Pages 335-342 in: Brighton Crop Protection, Pests and Diseases. Farnham, Surrey, UK.

5. Foster, J. M., and Hausbeck, M. K. 2010. Managing phytophthora crown and root rot in bell pepper using fungicides and host resistance. Plant Dis. 94:697-702.

6. Gengotti, S., Censi, D., Sbrighi, C., Antoniacci, L., and Bugiani, R. 2008. Evaluation of different fungicides against downy mildew (Pseudoperonospora cubensis) on open field zucchini and melon in Emilia-Romagna (Italy). Pages 461-466 in: Giornate Fitopatologiche 2008. Cervia (RA), Italy.

7. Gisi, U., Chin, K. M., Knapova, G., Farber, R. K., Mohr, U., Parisi, S., Sierotzki, H., and Steinfeld, U. 2000. Recent developments in elucidating modes of resistance to phenylamide, DMI and strobilurin fungicides. Crop Prot. 19:863-872.

8. Gisi, U., and Staehle-Csech, U. 1988. Resistance risk evaluation of new candidates for disease control. Pages 101-106 in: Fungicide Resistance in North America, C. J. Delp, ed. American Phytopathological Society, St. Paul, MN.

9. Gisi, U., Waldner, M., Kraus, N., Dubuis, P. H., and Sierotzki, H. 2007. Inheritance of resistance to carboxylic acid amide (CAA) fungicides in Plasmopara viticola. Plant Pathol. 56:199-208.

10. Glosier, B. R., Ogundiwin, E. A., Sidhu, G. S., Sischo, D. R., and Prince, J. P. 2008. A differential series of pepper (Capsicum annuum) lines delineates fourteen physiological races of Phytophthora capsici. Euphytica 162:23-30.

11. Goodwin, S. B., Sujkowski, L. S., and Fry, W. E. 1996. Widespread distribution and probable origin of resistance to metalaxyl in clonal genotypes of Phytophthora infestans in the United States and western Canada. Phytopathology 86:793-800.

12. Granke, L. L., Windstam, S. T., Hoch, H. C., Smart, C. D., and Hausbeck, M. K. 2009. Dispersal and movement mechanisms of Phytophthora capsici sporangia. Phytopathology 99:1258-1264.

13. Hausbeck, M. K., and Lamour, K. H. 2004. Phytophthora capsici on vegetable crops: research progress and management challenges. Plant Dis. 88:1292-1303

14. Jackson, K. L., Yin, J. F., Csinos, A. S., and Ji, P. S. 2010. Fungicidal activity of fluopicolide for suppression of Phytophthora capsici on squash. Crop Prot. 29:1421-1427.

15. Kaur, R., Thind, T. S., and Goswami, S. 2010. Profiling of Phytophthora infestans populations for metalaxyl resistance and its management with novel action fungicides. J. Mycol. Plant Pathol. 40:14-21.

16. Kousik, C. S., and Keinath, A. P. 2007. Sensitivity of Phytophthora capsici isolates from the southeast US to fluopicolide and cyazofamid. Page 20 in: Int. Phytophthora capsici Conf. Islamorada, FL.

17. Lamour, K. H., and Hausbeck, M. K. 2000. Mefenoxam insensitivity and the sexual stage of Phytophthora capsici in Michigan cucurbit fields. Phytopathology 90:396-400.

18. Latorse, M. P., and Kuck, K. H. 2006. Phytophthora infestans: baseline sensitivity and resistance management for fluopicolide. PflanzenchutzNachr. Bayer 59:317-322

19. Lu, X. H., Zhu, S. S., Bi, Y., Liu, X. L., and Hao, J. J. 2010. Baseline sensitivity and resistance-risk assessment of Phytophthora capsici to iprovalicarb. Phytopathology 100:1162-1168.

20. Ma, Z., and Michailides, T. J. 2005. Advances in understanding molecular mechanisms of fungicide resistance and molecular detection of resistant genotypes in phytopathogenic fungi. Crop Prot. 24:853-863.

21. Miller, P. M. 1955 . V-8 juice agar as a general-purpose medium for fungi and bacteria. Phytopathology 45:461-462.

22. Moss, M. A. 1987. Resistance to metalaxyl in the Pseudoperonospora cubensis population causing downy mildew of cucumber in south Florida. Plant Dis. 71:1045

23. Ojiambo, P. S., Paul, P. A., and Holmes, G. J. 2010. A quantitative review of fungicide efficacy for managing downy mildew in cucurbits. Phytopathology 100:1066-1076

24. Quesada-Ocampo, L. M., Fulbright, D. W., and Hausbeck, M. K. 2009. Susceptibility of fraser fir to Phytophthora capsici. Plant Dis. 93:135-141.

25. Rekanovic, E., Stepanovic, M., Milijasevic, S., Todorovic, B., Potocnik, I., and Duduk, B. 2009. Efficacy of new fungicide mixtures in controlling Phytophthora infestans (Mont.) de Bary in Serbia. Acta Hortic. 830:563-568.

26. Russell, P. E. 2004. Sensitivity Baseline in Fungicide Resistance Research and Management. FRAC Monogr. No. 3. Global Crop Protection Federation, Brussels.

27. Shattock, R. C. 1988. Studies on the inheritance of resistance to metalaxyl in Phytophthora infestans. Plant Pathol. 37:4-11.

28. Shin, J., Kim, J., Kim, H., Kang, B., Kim, K., Lee, J., and Kim, H. T. 2010 Efficacy of fluopicolide against Phytophthora capsici causing pepper Phytophthora blight. Plant Pathol. J. 26:367-371.

29. Smith, C. M. 1988. History of benzimidazole use and resistance. Pages 23 24 in: Fungicide Resistance in North America. C. J. Delp, ed. American Phytopathological Society, St. Paul, MN

30. Toquin, V., Barja, F., Sirven, C., and Beffa, R. 2007. Fluopicolide, a new anti-oomycetes fungicide with a new mode of action inducing perturbation of a spectrin-like protein. Pages 675-682 in: Modern Crop Protection Compounds, W. Kramer and U. Schirmer, eds. Wiley-VCH.

31. Toquin, V., Barja, F. Sirvan, C., Gamet, S., Latorse, M. P., Zundel, J. L. Schmitt, F., and Beffa, R. 2006. A new mode of action for fluopicolide: modification of the cellular localization of spectrin-like protein. Pflanzenschutz Nachr. Bayer 59:171-184.

32. Young, D. H., and Slawecki, R. A. 2004. Cross-resistance relationships between zoxamide, carbendazim and diethofencarb in field isolates of Botrytis cinerea and other fungi. Pages 125-131 in: Modern Fungicides and Antifungal Compounds IV. H. W. Dehen, U. Gisi, K. H. Kulk, P. E. Pussell and H. Lyr, eds. Friedrichroda, Thuringia, Germany.

33. Young, D. H., Spiewak, S. L., and Slawecki, R. A. 2001. Laboratory studies to assess the risk of development of resistance to zoxamide. Pest Manage. Sci. 57:1081-1087.

34. Zhu, S. S., Liu, X. L., Wang, Y., Wu, X. H., Liu, P. F., Li, J. Q., Yuan, S. K., and Si, N. G. 2007. Resistance of Pseudoperonospora cubensis to flumorph on cucumber in plastic houses. Plant Pathol. 56:967-975. 